\title{
O ENFRENTAMENTO DO MEDO DA MORTE ATRAVÉS DA COMPAIXÃO EM ARTHUR SCHOPENHAUER
}

Milene Dayana Paes Lobato ${ }^{1}$

Resumo: O maior terror do ser humano é a morte. É a parte mais sombria que em todas as épocas é marcada por uma negação constante de sua chegada. Sempre houve uma busca incessante de meios e métodos para retardar ou até superar a morte e o seu temor. Segundo Schopenhauer, o ser humano é constituído por Vontade e o mundo é a sua representação, isso significa que o indivíduo é essencialmente egoísta. A compaixão é o oposto do egoísmo e traz consigo, como compreenderemos no texto, uma certa "passagem" para o enfrentamento do maior temor humano: o medo da morte. Através de obras como As Dores do Mundo e o Mundo como Vontade e Representação, utilizaremos da Filosofia de Schopenhauer para explicar como a compaixão ajuda no enfrentamento dos medos existenciais.

Palavras-chave: Compaixão; Egoísmo; Medo da morte.

\section{COPING WITH THE FEAR OF DEATH THROUGH COMPASSION IN ARTHUR SCHOPENHAUER}

Abstract: The greatest terror of the human being is death. It is the darkest part that in all times is marked by a constant denial of its arrival. There has always been an unceasing search for means and methods to slow down or even overcome death and fear. According to Schopenhauer, the human being is constituted by Will and the world is his representation, this means that the individual is essentially selfish. Compassion is the opposite of selfishness and brings with it, as we will understand in the text, a certain "passage" to face the greatest human fear: the fear of death. Through works such as The Pains of the World and the World as Will and Representation, we will use Schopenhauer's Philosophy to explain how compassion helps in coping with existential fears.

Keywords: Compassion; Selfishness; Fear of Death.

\footnotetext{
${ }^{1}$ Licenciada Plena em Filosofia pela Universidade do Estado do Pará, Mestranda em Filosofia na Universidade Federal do Pará. Currículo Lattes: http://lattes.cnpq.br/1308566435876482
} 


\section{O Mundo como Vontade e Representação do homem}

O primeiro Livro de O Mundo como Vontade e Representação tem como título "Do mundo como Representação", sobre ela, entendemos como tudo aquilo que existe e que é explicado e representado a partir de nós mesmos. Tudo o que existe é representação minha. O que entendo por vida, terra, água, entre outros, são frutos da minha representação: o mundo é a minha representação, se eu findo, o mundo finda comigo também. Apenas o ser humano é capaz de trazer esse entendimento à consciência refletida e abstrata. Essa é a única verdade a priori: que o mundo existe apenas como representação. Todos os objetos existentes, inclusive o próprio corpo, devem ser entendidos dessa maneira. No que diz respeitos às coisas abstratas, devem ser entendidas como Vontade: "o outro lado do mundo. Pois assim como este é, de um lado, inteiramente REPRESENTAÇÃO, é, de outro, inteiramente VONTADE" (SCHOPENHAUER W II, 2015, p. 5).

A filosofia de Schopenhauer é fundamentada em uma filosofia da vontade que é o centro, a essência e a coisa-em-si do mundo. Todas as coisas são formas da objetivação da vontade, o princípio fundamental da natureza no perpétuo movimento de vida e de morte. A vontade é cega, arbitrária, tirânica e brutal, não possuindo nem um Deus que a controle, transformando o mundo em algo cruel, sendo responsável por todo o sofrimento da vida, no qual a razão não pode dar significado algum à existência - essa é a natureza causal da existência; a impossibilidade de uma felicidade plena em um mundo de sofrimento e dor, onde sempre haverá a insatisfação humana. A vontade é dor e também a sua causa - é o torturador e o torturado -, porque não haverá satisfação total do desejo. Portanto, se a essência da existência é dor, nada podemos fazer com relação a isso; nem a respeito da vida de dores e muito menos a respeito da morte que uma hora ou outra chegará; isto é, a existência sempre será o instante entre o não-ser antes da vida e a morte (não-ser após a vida).

Para Schopenhauer, o mundo é constituído de Vontade que é sempre cruel, tirânica, nos impossibilita de alcançar uma felicidade plena, fundamenta o indivíduo no egoísmo e é o que gera o temor à morte - pois a Vontade sempre quer mais vontade de vida. Com esse pensamento, o filósofo desconstrói a noção metafísica de mundo, como diz em sua obra As Dores do Mundo:

Não conheço nada mais absurdo que a maior parte dos sistemas metafísicos, que explicam o mal como uma coisa negativa; só ele, pelo contrário, é positivo, visto que se faz sentir. (...) A vida do homem é um combate perpétuo, não só contra males abstratos, a miséria ou o aborrecimento, mas também contra os outros homens... Trabalho, tormento, desgosto e miséria, tal é sem dúvida durante a vida inteira o quinhão de quase todos os homens. O mundo é o inferno, e os homens dividem-se em almas atormentadas e em 
diabos atormentadores.... Onde foi Dante buscar o modelo e o motivo do seu ‘inferno’ senão no mundo real? (SCHOPENHAUER, 2014, p. 25).

Toda satisfação das necessidades pessoais do indivíduo, a realização dos desejos particulares, tudo é ilusório e temporário, a condição do ser é carência e sofrimento, como dizia Schopenhauer "é um pêndulo que oscila entre a dor e o tédio" (W I, 4, § 57, 428).

"Cada história de vida é uma história de sofrimento"2, nossa existência está marcada por constantes desejos que não nos permitem satisfação, a não ser momentânea. Para Schopenhauer, nesse sentindo, o que a vida tem de melhor para a oferecer é justamente o que nos lamentamos constantemente: a brevidade da vida.

Em Schopenhauer, o fim último da existência não pode ser alcançado, pois ela provém de sentido e valor, justamente por ser Vontade: ela é, em absoluto, o que não deve ser, é a sua própria contradição. A significação do mundo vai além da razão, pois a razão é limitada e a Vontade não se limita às suas características. O que diferencia o homem do animal é a capacidade humana de originar representações abstratas e não somente intuitivas, o que nos permite refletir sobre as coisas e formular conceitos (conceitos são as próprias representações).

Todas as coisas são formas de objetivação da Vontade, sendo a Vontade de Vida a maior delas. A Vontade de Vida sempre existirá segundo possibilidade no homem, nada pode a suprimir a não ser o conhecimento. Qualquer coisa feita, para além disso, com o intuito de negar ou se desvincular da Vontade, será um ato falho, pois em vez de negar, afirmará os próprios desejos da Vontade. Somente o conhecimento é capaz de suprimir a Vontade e findar o sofrimento. A vontade de vida é responsável por todo querer, o conhecimento disso nos leva à ascese, à negação da Vontade (do querer):

\footnotetext{
ASCESE entendo, no seu sentido estrito, essa quebra PROPOSITAL da vontade, pela recusa do agradável e pela procura do desagradável, o modo de vida penitente voluntariamente escolhido e a autocastidade, tendo em vista a mortificação contínua da vontade. (SCHOPENHAUER, 2015, p. 454).
}

A compreensão da Vontade de Vida é que nos faz entender que ela é responsável tanto pelo sofrimento, quanto pelo medo inerente ao ser humano: o medo de morrer. A partir desse ponto que Schopenhauer explica, através da Metafísica da Morte, a origem do medo e a sua insignificância.

\footnotetext{
${ }^{2}$ O Mundo como Vontade e Representação I, §59, p. 376. 2015.
} 


\section{A metafísica e o medo da morte em Schopenhauer}

Para falar da concepção e o conceito de morte em Schopenhauer é preciso primeiro esclarecer o que é Vida para ele. O impulso à geração da vida - manifestação da Vontade - é eterno e ilimitado; porém, a vida expressa-se nos indivíduos que são feitos de matéria, portanto, limitados. Através dessa metafísica da Vontade, Schopenhauer esclarece a relação entre o homem e a morte. A metafísica da morte trata do ser mortal em contraste com a Vontade imortal. Isto é, vida e morte são partes do mesmo processo, ambos são um vir-a-ser, sendo um o complemento do outro, como diz Jair Barboza: "O homem, como vida, é um ser para morte"3. Em Parerga e Paralipomena, Schopenhauer diz o seguinte: "Porque te queixas da caducidade dos vivos? Como existiria eu, se todos da minha espécie que me precederam não estivessem mortos?" (SCHOPENHAUER. 2009, p. 140).

A partir do texto Metafísica da Morte, Schopenhauer inicia suas reflexões alegando que o maior temor do homem é a morte, tanto a sua quanto a de seus próximos - daí surge o conceito de compaixão que o filósofo afirma fazer parte da constituição humana. O homem se torna consciente da morte a partir da morte de outrem. Ao nos depararmos com a morte de alguém próximo, sentimos o pavor diante deste fenômeno. Compreende-se assim, que o tempo é algo ideal à natureza humana, pois a idealização dele é a chave para qualquer sistema metafísico; de certo que, de cada evento que vivemos, é por um momento apenas que podemos dizer que este é, após isso, devemos dizer para sempre que este foi. Sobre tal situação, Schopenhauer escreve o seguinte:

Se o que faz a morte nos parecer tão assustadora fosse a ideia do não-ser, então deveríamos experimentar o mesmo temor diante do tempo em que ainda não éramos. Pois é incontestável que o não-ser do depois da morte não pode ser diferente daquele anterior ao nascimento; ele não merece, portanto, ser mais lamentado. (SCHOPENHAUER, W II, 2015, § 531, p. 559).

Apenas os homens são capazes de conhecerem a morte por conta de sua racionalidade, diferentemente dos animais que conhecem a morte, no entanto, possuem o temor de forma a priori e não refletem sobre ela. O animal, segundo o filósofo, evita a morte de maneira instintiva, já o homem, além de evitas os perigos da vida que podem o levar a morte, ele cria religiões que

\footnotetext{
${ }^{3}$ BARBOZA, Introdução. In Metafísica do Amor, Metafísica da Morte, 14.
} 
podem o consolar, como um remédio capaz de aliviar as perturbações que a ideia da morte nos causa. Assim, para o filósofo, o apego à vida é:

(...) irracional e cego: só é explicável pelo fato de que todo nosso ser em si mesmo já é Vontade de vida, ... e pelo fato que a Vontade em si é originalmente destituída de conhecimento e cega. O conhecimento, ao contrário, bem longe de ser a origem ao apega à vida, atua contra este, na medida em que desvela a ausência de valor da mesma e, assim, combate o temor a morte (SCHOPENHAUER, 2000, p. 64).

Para o filósofo, a natureza que nunca mente deixa explícita a nossa condição existencial, que é não-ser antes e depois da vida. Portanto, ao tratar do problema da morte, Schopenhauer conclui que, se analisarmos racionalmente os motivos que nos levam a temê-la, veremos que eles são injustificáveis. Isto é, o não-ser após a morte é similar ao não-ser anterior ao nascimento. Inúmeras coisas existiram antes de nós, mas isso não nos causa tanta aflição quanto ao que existirá após a nossa morte. O autor dirá o seguinte:

A infinitude a parte post (posterior) sem mim pode ser tão pouco terrível quanto a infinitude a parte ante (anterior) sem mim, na medida em que ambas em nada se diferenciam a não ser pela mediação de um sonho efêmero da vida... e é tão absurdo afligir-se sobre o tempo em que não mais se será, quanto o seria sobre o tempo em que ainda não éramos: pois é indiferente se o tempo, não preenchido pela nossa existência, relaciona-se como futuro ou passado àquele que ela preenche (SCHOPENHAUER, 2000, p. 67).

Para Schopenhauer a morte "é propriamente o gênio inspirador, ou a musa da filosofia (...). Dificilmente se teria filosofado sem a morte" (SCHOPENHAUER, W II, 2015, p. 555). No entanto, a própria Vontade cega construiu uma história na humanidade que levou a mudanças concretas com relação ao entendimento da morte; todo ser humano possui em si a fuga mortis (fuga da morte), proveniente da Vontade cega, o que causa no homem a supervalorização da vida em detrimento da morte.

Para o Schopenhauer, a religião é reflexo da necessidade metafísica do ser humano, necessidade essa que nasce da consciência em face da morte - por isso que somente o ser humano possui essa necessidade, só ele tem consciência da morte, não apenas de forma instintiva como nos animais. Assim,

podemos pensar que o consolo para a morte que as religiões proporcionam ao renovar a esperança dos seus fiéis em outra vida é uma artimanha do querer da Vontade que impulsiona a razão a criar o artifício metafísico das religiões, o qual abraça a maioria das pessoas que dão continuidade à perpetuação da 
espécie, ou seja, afirmam inconscientemente o próprio querer da Vontade (MEDEIROS, 2018, p. 60).

Para Schopenhauer, é o próprio saber diante da morte e a nossa compreensão sobre a miséria e sofrimento da vida que nos estimula à interpretação metafísica do mundo; se a vida fosse sem sofrimentos e sem fim, de que serviriam os deuses? Se a imortalidade fosse possível de alguma maneira, o zelo pelos deuses deixaria de existir pelo simples fato deu não necessitar mais deles.

Templos e igrejas, pagodes e mesquitas, em todos os países, em todos os tempos, no esplendor e na grandeza, testemunham a necessidade metafísica do ser humano, necessidade que, forte e inextirpável, pisa os calcanhares da necessidade física. Decerto, alguém com humor satírico poderia acrescentar que essa necessidade metafísica é uma garota humilde que se contenta com cardápios bem modestos (SCHOPENHAUER, W II, 2015, p.197).

Mas para o filósofo alemão, a morte deve ser entendida como uma solução aos sofrimentos do mundo e um cessar das dores existenciais. Em Parerga e Paralipomena (Sobre a Filosofia e seu Método), o filósofo diz que "o caráter fundamental de todas as coisas é a transitoriedade" (SCHOPENHAUER, 2010, p. 140), isso vale também para o entendimento de nossa existência.

Assim, a questão principal levantada é a noção infundada de que o desaparecimento do corpo aniquilará o princípio da vida, o que constitui o temor à morte. Quando desvelamos a vida, há uma mudança entre o nada-inicial (antes da vida) e o não-ser-final (depois da vida morte), talvez seja por conta disso que Schopenhauer constata o seguinte

Quantas belas declamações não temos sobre quanto seria chocante a ideia de que o espírito do homem, esse espírito capaz de abarcar o mundo, pleno de tão elevados e excelentes pensamentos, também descesse para o túmulo! Mas sobre o fato de como esse espírito deixou passar toda uma infinidade de tempo antes de ter nascido com estes seus atributos, e que o mundo, durante todo esse tempo, tenha se arranjado sem ele, não se ouve uma palavra. (SCHOPENHAUER W II, 2015, p. 559).

Compreendemos, a partir de Schopenhauer, que o temor à morte vem do conhecimento do princípio de razão suficiente que serve somente à vontade individual. A morte para o sujeito é apenas um cessar da consciência, da atividade cerebral, sendo a consciência apenas o efeito e resultado da vida orgânica, e não a causa dela - Schopenhauer compara a morte como um 
desmaio ou um sono, pois em ambas situação existem a perca da consciência: “(...) o sono é o irmão e o desmaio é o gêmeo da morte" (SCHOPENHAUER, 2000, p. 69). Assim, o carpe diem é sucumbido quando tentamos "aproveitar o dia" como se a morte não fizesse parte de seu ciclo existencial.

As consequências desse acontecimento são angústias e frustrações de não conseguir alcançar a eternidade, dedicando-se a ter uma vida mais longa para poder aproveitá-la, mas "deixando de viver" por perder tanto tempo buscando "viver mais". Como diz Epicuro em uma missiva a Meneceu: "acostuma-te à ideia de que a morte, para nós, é um nada. Todo bem e todo mal reside na faculdade de sentir; a morte, porém, é a privação desse sentimento. Assim, o conhecimento de que a morte nada é torna deliciosa nossa vida efêmera" ${ }^{4}$. Em outro trecho da epístola, o filósofo diz o seguinte:

Assim a morte, o mais temível de todos os males, é para nós um nada: enquanto nós existimos, não existirá ela, e quando ela chegar, nada mais seremos. Desse modo, a morte não toca nem os vivos nem os mortos, porque onde estão os primeiros não se encontra ela, e os últimos já não existem mais. (EPICURO, 2006, p. 39).

Desta maneira, faz-se necessário especificar o medo da morte em Schopenhauer e os impactos que provocaram na história da humanidade - como a fuga constante da morte, a criação de religiões que amenizam o temor à morte. Tratar o além da morte física, a transmigração da alma (metempsicose) - enquanto transmigração da Vontade - e a relevância em aceitar a morte e os meios usados pelo filósofo para aliviar as angústias humanas são cruciais para compreender o que fundamenta o temor da morte na sociedade hodierna e como é possível uma superação deste medo.

Para Schopenhauer, o "querer viver" do ser racional é a raiz de todos os males, pois a insatisfação de não conseguir alcançar a infinitude, gera ansiedade e angústia. Só o homem tem completa noção de que vai morrer e desaparecer, essa característica é o que diferencia o animal do ser humano e também origina o temor à morte, porém, ao compreender que somos manifestação da Vontade indestrutível, não temeremos a morte, pois a Vontade não é afetada por ela. A morte destrói apenas o indivíduo, porém, o impulso do temor à morte é reflexo da Vontade que quer vida, e isto produz no fenômeno finito do organismo um sentimento de medo.

\footnotetext{
${ }^{4}$ EPICURO, Carta a Meneceu, p. 38.
} 
A vida da maioria das pessoas é tão somente uma luta constante por essa existência mesma, com a certeza de ao fim serem derrotadas. O que as faz, por tanto tempo, travar essa luta árdua não é tanto amor à vida, mas sim temor à morte, que, todavia, coloca-se inarredável no pano de fundo, e a cada instante ameaça entrar em cena. - A vida mesma é um mar cheio de escolhos e arrecifes, evitados pelo homem com grande precaução e cuidado, embora saiba que, por mais que seu empenho e arte o leve a se desviar com sucesso deles, ainda assim, a cada avanço, aproxima-se do total, inevitável, irremediável naufrágio, sim até mesmo navega direto para ele, ou seja, para a morte. Este é o destino final da custosa viagem e, para ele, pior que todos os escolhos que evitou (SCHOPENHAUER W I, 2015, p. 403).

O medo de morrer é como um mecanismo de defesa da Vontade que quer viver. A questão da morte em Schopenhauer possui íntima ligação com o sofrimento humano e corrobora com a ideia de que viver é sinônimo de sofrer. Esse sofrimento é fruto de um esforço para suprir uma carência insaciável que está na raiz da essência do mundo, isto é, a Vontade. O Mundo como Vontade e Representação nos aponta que, inevitavelmente, seremos, enquanto indivíduos, aniquilados com a morte.

\section{O egoísmo e a compaixão em Schopenhauer}

Como já compreendemos ao longo do artigo, cada indivíduo, ser e coisa que existe na natureza, é Vontade de vida. O fundamento e a essência do egoísmo estão nesse ponto: "Somente eu sou tudo em tudo: a única coisa que importa é a minha conservação, o resto pode perecer, pois, propriamente dizendo, não e nada" (SCHOPENHAUER, W II, 2015, p. 716), esse é o ponto de vista particular característico da natureza, que nos baseia e baseia o egoísmo em cada ser humano.

O egoísmo é o motor que impulsiona os animais e os homens à existência. Eles possuem a preocupação com o próprio bem-estar, que Schopenhauer chama de egoísmo sensitivo, que sempre quer estar a salvo.

Sob o ponto de vista da Vontade, cada indivíduo, ao se reconhecer enquanto Vontade em si, que constitui tudo na natureza, acha-se como "infinitamente importante". Mas quando olhamos sob a perspectiva da Representação, o homem é insignificante, pois é apenas um indivíduo perante milhares de outros indivíduos. O egoísmo deriva, portanto, da perspectiva que temos sob nós mesmos, nossos próprios olhos que nos olham. A consequência disso é o total desprezo que temos com o outro, por ser considerado por nós como um não-eu.

A morte, aqui, já aparece como a correção da Vontade de Vida no curso da natureza, esse egoísmo é dizimado pela morte quando ela nos mostra que nós não existimos sem o outro, 
ou seja, tudo o que o egoísta acredita ser dele e por ele, a morte mostra que o "eu" sempre viveu no que ele considerado "não-eu" - o que o constitui está em todos, no caso, a Vontade.

No fundo somos algo que não deveria ser: por isso cessamos de ser. - $\mathrm{O}$ egoísmo consiste em verdade no fato de que o ser humano limita toda a realidade à sua pessoa, pois se imagina existir apenas nessa pessoa, não nas outras. (SCHOPENHAUER, W II, 2015, p. 605).

Por conta da Vontade ser ilimitada, o egoísmo também é ilimitado, o homem se utiliza de qualquer meio para sua própria conservação, sempre busca se livrar de todas as dores.

A compaixão surge em relação à necessidade do ser humano ter contato com o sofrimento. Esse contato é necessário para começar o exercício de compaixão, quando reconhecemos o sofrimento não só em nós, mas tamb'ém no outro. Esse sofrimento se mostra como nada mais do que a essência que se manifesta em mim e no outro: a Vontade. Aqui devemos entender que não é possível saber o sofrimento do outro, mas conseguimos saber o que é sofrer, isso já é o suficiente para nos tornarmos aptos a reconhecer o sofrimento do outro. Para isso, precisamos não somente da presença do sofrimento, mas do conhecimento do sofrimento:

\begin{abstract}
Nesse sentido, por exemplo, para que a proporção existente numa dada pessoa entre egoísmo e compaixão entre em cena, não é suficiente que essa pessoa possua riqueza e veja a miséria alheia; ela também tem de saber o que é permitido fazer com a riqueza, tanto em seu favor como para os outros; ademais, o sofrimento alheio tem não apenas de expor-se a ela, mas ela também tem de saber o que é o sofrimento e o que é o prazer. (SCHOPENHAUER, W I, 2015, p. 341-342).
\end{abstract}

O sofrimento é inevitável e universal, como dito antes, cada história de vida é uma história de sofrimento. No Hinduísmo, citado por Schopenhauer no Livro IV do Mundo como Vontade e Representação, tomo I, por compaixão, doutrinam melhor as pessoas quando os fazem entender que somos feitos de nada "e devem agradecer e alegrar-se por isso".

A compaixão é a superação do principium individuations, capaz de compreender para além de si mesmo, identificando-se com o sofrimento de outrem. Todo amor, amor puro, é compaixão:

Portanto, o que a benevolência, o amor e a nobreza de caráter podem fazer pelos outros é sempre apenas o alívio dos seus sofrimentos; conseguintemente, o que nos pode mover a bons atos e a obras de amor é sempre e tão somente o CONHECIMENTO DO SOFRIMENTO ALHEIO, compreensível imediatamente a partir do próprio sofrimento e posto no mesmo patamar deste. (SCHOPENHAUER, W I, 2015, p. 436). 
A compaixão, portanto, é essa identificação da dor em si e no outro, assim, o choro, por exemplo, é a compaixão de si mesmo que "retorna ao seu ponto de partida". Esse é o fundamento moral na Ética de Schopenhauer. O conceito de compaixão é o que impede o niilismo em sua filosofia, e nos dá uma saída para o egoísmo inerente à Vontade que nos constitui. Aqui, deixamos de pensar somente em nossa dor, em nossa sobrevivência e começamos a olhar para o outro, sem as contradições entre "eu" e não-eu", mas apenas como "companheiros de sofrimento".

\section{O enfrentamento do medo da morte através da Compaixão}

Schopenhauer é muito transparente com relação ao homem egoísta, afirma que este homem não serve para nada, pois sempre usa o outro como instrumento para benefício próprio. O egoísmo não tem limites e faz o homem ter apenas um desejo em absoluto: conservar a sua existência e fugir de qualquer dor, tudo o que o impedir de alcançar esse objetivo, ele aniquila.

Apesar de todo sofrimento do mundo, existe um sentimento que consegue transcender todo o egoísmo humano, sentimento este que também fundamenta a ética e que podemos compreender como o único que nos possibilita uma passagem para o enfrentamento do medo da morte: a compaixão. Apesar de toda crueldade que envolve a existência, a piedade e a compaixão são sentimentos apostos ao egoísmo. O egoísmo é fruto do "ego" (eu), que faz o indivíduo sentir-se centro do universo, se opondo a tudo que impossibilite seu próprio bemestar. A compaixão é a grande chave para a fuga do egoísmo, pois ela está além da nossa própria representação de mundo:

Por isso, desejo, em oposição à forma referida do princípio moral kantiano, estabelecer a seguinte regra: com cada pessoa com que tenhamos contato, não empreendamos uma valorização objetiva da mesma conforme valor e dignidade, não consideremos portanto a maldade da sua vontade, nem a limitação do seu entendimento, e a incorreção dos seus conceitos, porque o primeiro poderia facilmente ocasionar ódio, e a última, desprezo; mas observemos somente seus sofrimentos, suas necessidades, seu medo, suas dores. Assim, sempre teremos com ela parentesco, simpatia e, em lugar do ódio ou do desprezo, aquela compaixão que unicamente forma a ágape pregada pelo evangelho. (SCHOPENHAUER, 2002, p.188).

Isto é, a compaixão é o que nos faz compreender que nesse mundo de dor e sofrimento, o outro sofre tanto quanto eu e isso além de nos aproximar, nos faz enfrentar diversos medos 
para lidar com a dor do outro. Quando alguém morre, automaticamente nós sentimos sua dor e o temor que isso causou a esta pessoa. Este acontecimento nos faz enfrentar nossos próprios medos a fim de confortar a dor do outro. Schopenhauer em As Dores do Mundo diz o seguinte:

Não há senão três causas fundamentais das ações humanas, e nada se faz sem elas. Temos: a) o egoísmo, que quer o seu próprio bem (não tem limites); b) a maldade, que deseja o mal de outrem (vai até a extrema crueldade); c) a piedade, que quer o bem de outrem (vai até a generosidade, à grandeza da alma). Toda ação humana depende de uma dessas três causas, ou mesmo de duas. (SCHOPENHAUER, 2014, p. 99).

Uma piedade sem limites, que envolve, como diz o filósofo, não só as pessoas como também os animais, é o fundamento seguro da moral. As consequências da piedade envolvem perdão, a disposição a prestar socorro, o agir justamente, o receio em causar danos aos outros, entre outras ações humanizadas.

A partir do momento que percebemos a mudança no relacionamento entre as pessoas, esquecemos o medo da morte quando nos disponibilizamos a amenizar a dor do outro, mesmo que isso possa também nos trazer dor. Enfrentamos hospitais superlotados e a exposição a doenças ou situações ruins com o intuito de diminuir o sofrimento do outro. A compaixão consegue, em sua grande maioria das vezes, superar o egoísmo, deixá-lo adormecido, pois naquele momento o que move o indivíduo é a piedade.

Compreendemos, portanto, que se em Schopenhauer a compaixão é o princípio fundamental da ética, os tempos sombrios da pandemia ao menos têm nos tornados mais éticos e piedosos, e consequentemente, menos egoístas. Somente a piedade é o princípio real de toda justiça livre e de toda verdadeira caridade. A piedade, a compaixão, não depende de nada a priori, nem religiões, dogmas, mitos, política, cultura ou qualquer outra coisa. O ser humano que não conhece a piedade e não sente compaixão - isto é, não consegue entender que o outro também sofre com as dores desse mundo - está completamente fora da humanidade, pois a compaixão é o princípio de toda humanidade. Esse sentimento traz consigo a coragem que eu preciso para enfrentar meus próprios medos - sendo o maior deles, o medo da morte - para ajudar o outro que sofre também, para "que todos os seres vivos se conservem isentos de dores!" (SCHOPENHAUER, 2014, p. 106).

\section{REFERÊNCIAS BIBLIOGRÁFICAS}


BARBOZA, Jair. Schopenhauer. Rio de Janeiro: Jorge Zahar, 2003.

BRUM, José Thomaz. O Pessimismo e suas Vontades: Schopenhauer e Nietzsche. Rio de Janeiro: Rocco, 1998.

CACCIOLA, Maria Lúcia. A morte, musa da Filosofia. In Cadernos de Filosofia alemã $\mathrm{n}^{\circ} 9$. São Paulo: Edusp, 2007.

DEBONA, Vilmar. A outra face do pessimismo: caráter, ação e sabedoria de vida em Schopenhauer. São Paulo: Edições Loyola, 2020.

DEBONA, Vilmar. Schopenhauer. São Paulo: Ideias \& Letras, 2019.

EPICURO. Carta a Meneceu. In Pensamentos: Epicuro. São Paulo: Martin Claret, 2006.

MEDEIROS, Victor H. M. de. A razão do sábio não temer a morte na filosofia de Arthur Schopenhauer. Natal (RN), 2018. Dissertação de Mestrado - Programa de Pós-Graduação em Filosofia, Universidade Federal do Rio Grande do Norte.

Ministério da Saúde. Disponível em: 〈https://www.saude.gov.br/boletins-epidemiologicos〉. Acesso em: 30 abril 2020.

PERNIN, Marie-José. Schopenhauer: decifrando o Enigma do Mundo. Trad Lucy Magalhães. Rio de Janeiro: Jorge Zahar, 1995.

SCHOPENHAUER, Arthur. A arte de conhecer a si mesmo. Trad Jair Barboza e organização de Franco Volpi. São Paulo: Martins Fontes, 2009.

SCHOPENHAUER, Arthur. Aforismos para a Sabedoria de Vida. Trad Jair Barboza. São Paulo: Martins Fontes, 2002

SCHOPENHAUER, Arthur. Dores do Mundo (O Amor - A Morte - A Arte - A moral - A Religião - A Política - O Homem e a Sociedade). São Paulo: Edipro, 2014.

SCHOPENHAUER, Arthur. Metafísica do Amor, Metafísica da Morte. Trad Jair Barboza. São Paulo: Martins Fontes, 2000.

SCHOPENHAUER, Arthur. O Mundo como Vontade e Representação - Tomo I. 2 ed. São Paulo: UNESP, 2015.

SCHOPENHAUER, Arthur. O Mundo como Vontade e Representação - Tomo II. 2 ed. São Paulo: UNESP, 2015.

SCHOPENHAUER, Arthur. Parerga e Paralipomena II. Trad. Wolfgang Leo Maar. In Os Pensadores. São Paulo: Abril Cultural, 1980.

SCHOPENHAUER, Arthur. Parerga y Paralipómena II. Trad. y notas de Pilar de López. Espanha: Trotta, 2009.

SIMMEL, Georg. Schopenhauer \& Nietzsche. Trad. César Benjamin. Rio de Janeiro: Contraponto, 2011. 
Artigo recebido em: 30/07/2020

Artigo aprovado em: 05/10/2020 